\title{
Computer Game and Wearable Sensors Based Approach to Promote Physical Activity for Young Men
}

\begin{tabular}{|c|c|}
\hline Heli Koskimäki ${ }^{1}$ & ${ }^{2}$ Cultural Antropology \\
\hline Pekka Siirtola ${ }^{1}$ & University of Oulu \\
\hline Eino Keskitalo ${ }^{1}$ & ${ }^{3}$ Research Unit of Medical \\
\hline Lauri Tuovinen ${ }^{1}$ & Imaging, Physics and \\
\hline Tim Luoto $^{2}$ & Technology \\
\hline Riikka Ahola ${ }^{3}$ & University of Oulu \\
\hline Riitta Pyky ${ }^{3,4,5,6}$ & ${ }^{4}$ Department of Sports and \\
\hline Raija Korpelainen $^{4,5,6}$ & Exercise Medicine \\
\hline Timo Jämsä ${ }^{3,6,7}$ & Oulu Deaconess Institute \\
\hline Hannu Heikkinen ${ }^{2}$ & ${ }^{5}$ Center of Life Course Health \\
\hline Juha Röning $^{1}$ & $\begin{array}{l}\text { Research } \\
\text { University of Oulu }\end{array}$ \\
\hline${ }^{1}$ Biomimetics and Intelligent & ${ }^{6}$ Medical Research Center Oulu \\
\hline Systems Group & University of Oulu and University \\
\hline University of Oulu & Hospital of Oulu \\
\hline PO Box 4500 & ${ }^{7}$ Department of Diagnostic \\
\hline 90014 University of Oulu & Radiology \\
\hline Finland & Oulu University Hospital \\
\hline
\end{tabular}

Permission to make digital or hard copies of part or all of this work for personal or classroom use is granted without fee provided that copies are not made or distributed for profit or commercial advantage and that copies bear his nolice and the full citation on the first page. Copyrights for third-party components of this work must be ho

UbiComp/ISWC'17 Adjunct, September 11-15, 2017, Maui, HI, USA (2017 Copyright is held by the owner/author(s).

https://doi.org/10.1145/3123024.3124433

\begin{abstract}
In this work, it was tested if a computer game and wearable sensors could be used to motivate young men to increase their everyday activity. The game itself was planned so that the possibility to play the game and success in it was dependent of how much activity the subject achieved during his everyday life. A pilot version of a computer game, called Space Pioneer, was developed for this purpose while the activity measures were collected using three type of sensors: pedometer, Polar Active activity monitor or mobile phone application. The results were varying; although many subjects did not even try the game or disliked it, the awareness of subjects' own physical condition as well as daily activity information were found out to be motivating factors in the target group.
\end{abstract}

\section{ACM Classification Keywords}

H.1.2. [Information Systems]: User/Machine Systems

\section{Author Keywords}

Serious games; Wearable Sensors; Physical activity; Activity monitoring; Awareness.

\section{Introduction}

Globally, physical inactivity causes 1.9 million deaths per year [2] because of its several adverse health effects [4].

Decreasing amount of physical activity and increasing seden- 
tary behaviour especially among adolescents is a growing concern [11]. Amongst the young, inactive subjects are not often aware of the fact that they are insufficiently active [8]. It is well established that increasing physical activity improves health by reducing obesity and associated cardiovascular and metabolic risk factors [4].

There is little evidence to support any specific activation program, and at present it is not known what the most appropriate method for promoting physical activity among young men would be. The Pokemon Go, targeted to slightly younger population, succeeded to increase activity of masses but also with it the enthusiasm relented rapidly. Interventions to promote physical activity have typically involved teaching individuals the skills to change physical activity behaviour, providing knowledge about physical activity goals or opportunities to be active, or creating a more physically active environment [14].

There is indicative evidence that internet-based physical activity interventions can be more effective than other methods. As a result of the rapid development of the internet it is now possible to distribute feedback to a wide range of people and settings in a low cost manner [14], [10]. Among young adults one effective way to convey health information and affect health behaviour could be through games. RCT trials show successful interventions through the use of games [13] and improved health-related behaviour [6]

This study is a part of multidisciplinary MOPO project which combines traditional health promotion, modern technology and measurement of physical activity. The aim of the MOPO study was to provide knowledge on the physical activity, relationship towards physical activity, information behavior, fitness, health, nutrition, life habits and cultures of young men. [12], [1]

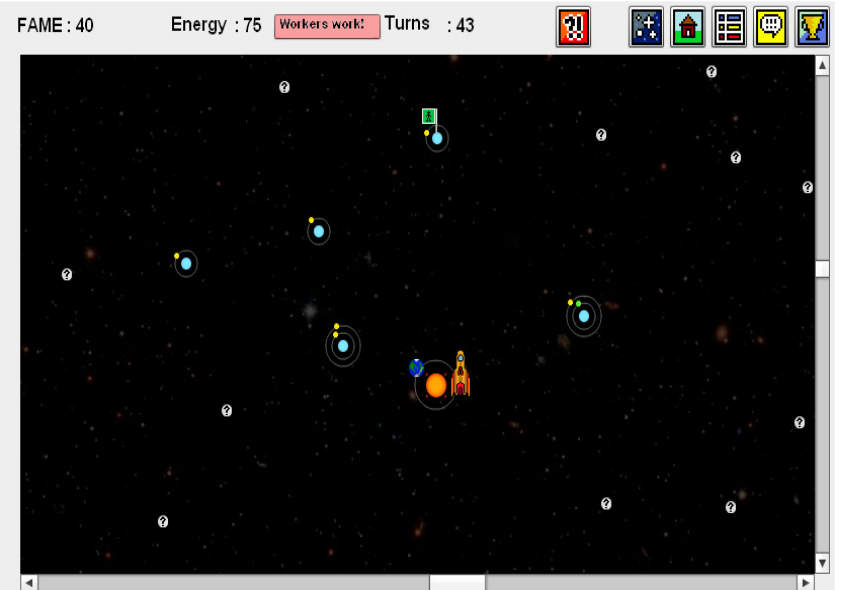

Figure 1: Space Pioneer.

While the MOPO studies concentrate on overall activity as well as on physical activity using a gamified coaching service, this study concentrates on the physical activity motivation. However, in this study we approach the persuasion for physical activity in an unorthodox manner: instead of motivating user directly towards more active lifestyle the user is motivated to play the computer game, Space Pioneer. However, daily activity measures are used as game input thus the playing of the game and success in it correspond to the daily activity levels.

\section{Activation game and used sensors}

For the study, a novel computer game called Space Pioneer was developed. The game is a Flash-based, lightweight, Retro style, multiplayer game with a space exploration theme, playable in a web browser (Figure 1).

In the first phase of the game, the surrounding space is 


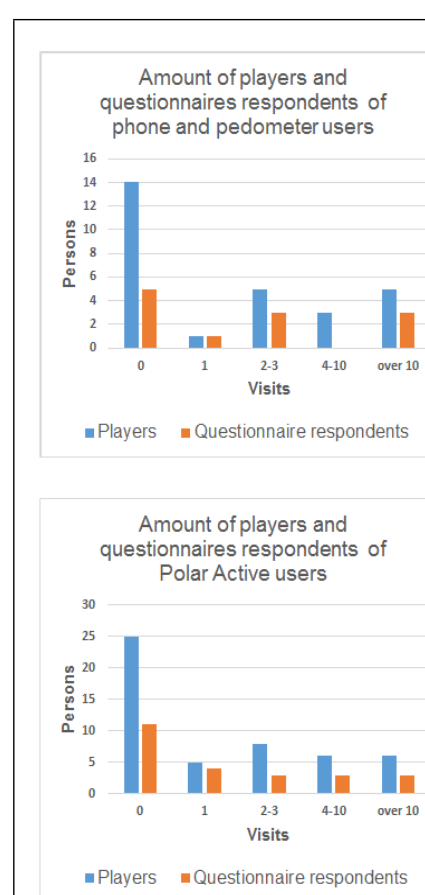

Figure 2: Visit categories and number of players in each category in Space Pioneer and in questionnaires answered. mapped, raw materials are mined from found planets, and a functional community is built on the player's home planet. The ultimate aim, however, is to find artifacts of ancient civilizations from the surrounding space. This awards the player the most points. During this study the game was developed as a limited prototype because of the limited amount of time. Thus at this point the game should be considered as a mock-up and not a fully developed game. The game was "complete" in the sense of being fully playable with a clear goal, but not rich in content and features.

In the game, daily activity measures are used with two ways. The collected activity is transferred into fuel for the space shuttle as well as energy of the workers who mine the raw minerals. When the fuel and energy run out the player is informed that he have to go moving to be able to continue playing. Thus the playing itself as well as success in it is dependent of the daily activity levels. Lighter activity awards the player fuel, while harder exercise awards the player energy. The aim was to differentiate the game for players with different levels of activity, and to persuade players towards heavier activity. This was attempted by keeping a portion of the game play (mining and the excavation of the artifacts) prohibited unless player became more active. At the same time, the space-exploration and mapping portion of the game was available even if the player was only lightly active.

The daily activity levels were measured using three different sensors: Omron Walking Style III pedometer, Polar Active activity monitor and mobile phone software developed during the project. The Omron Walking Style III is a small device that can be put into a pocket or attached with clip, for example, to belt [5]. It counts the daily steps, distance and energy consumption and has memory of 7 days. For the game purposes the daily counts were transferred into the game manually. Polar Active activity monitor is a wristworn activity monitor that can be used as a watch [7]. The device measures physical activity continuously and separates it in five different zones (very easy, easy, moderate, vigorous, vigorous+). In addition, it gives daily step counts and energy consumption and has memory of three weeks. To the game the data collected was transmitted automatically using Polar flowlink. The mobile phone software was developed for Symbian $\wedge 3$ operating system and the used phones were Nokia N8. The software used device's built-in accelerometers in order to recognize daily activities (walking, running, cycling, riding a car and idling) as well as the daily step counts [9]. The data from the phone was given manually as game input, although the data was transferred into a code to prevent cheating in the input phase.

Because the overall aim was to decrease sedentary activity, the time required to play the game was kept minimal. Thus the Space Pioneer itself was built so that a single play sessions duration is only few minutes, for example, the workers can be used to mine materials twice a day.

\section{Piloting and results}

The game was piloted in the annual military call-ups of Oulu area, Finland in 2011. During two weeks approximately 1500 conscription aged young men (mainly ages between 17 and 19 years) are gathered together enabling recruiting of volunteers for the study from whole age population. Approximately 80 volunteers were recruited for Space Pioneer tests $(20$ with pedometers, 50 with Polar Active and 8 with Nokia N8 application). All the volunteers were equipped with the appropriate devices, although few of them (4 subjects) had their own N8 devices and thus they were able to download the software via Internet. The pilot research lasted for three months, during which time all subjects were tested physically - both in the beginning and in the end of 
the research.

During the three months period approximately 40 boys of the 80 volunteers tested the game while the use rate of the sensors were higher. The lack of time and interest were explained to be the reasons for not playing. From the 40 boys who tested the game, approximately a fourth played quite regularly and a sixth tested the game only once. The more detailed game visits can be seen from Figure 2. After the three month trial period questionnaires were filled (36 boys from which 20 had tested the Space Pioneer). Although all the volunteers did not fill the questionnaires, the distribution in answer population responds to the distribution of the whole population as can be seen from Figure 2.

The different sensors were accepted quite well. The pedometers were told in interviews to be easiest to forget but the wrist-worn activity monitors and the phones were normally carried along. The negative drawback of the phone is that its carrying is impossible or difficult in plenty of different sporting activities, for example, in swimming and in ice hockey. However, if the monitor is used only to measure the daily activity without exercise information the phone is suitable. With the Polar Active activity monitor the negative feedback was given while the wrist-worn activity sensor did not recognize movements in which the hand did not move, for example, in cycling. Nevertheless, the wrist-worn activity monitor is a reliable and valid method for assessing energy expenditure during intensive training [3]. The scores given to different sensors can be seen from Figure 3. The attractiveness of the pedometers was considered lower than others but the overall grades were quite consistent with others. An interesting aspect, nevertheless, was that only a half would prefer the sensor they had during the three months and a half would like to have an another type of sensor. In addition, traditional heart rate monitor was wanted to be combined with the used sensors.

The opinions of the game, Space Pioneer were asked from the 40 volunteer who tested the game at least once. The feature scores are shown in Figure 4. The scores are presented as average from all the players but also as average of the most active players. Naturally, the more active players responded more positively to the game. The idea of the integration of the game and daily activity was considered good within both groups and the usability was not an obstacle. Nevertheless, the incomplete version of the game got negative feedback. For example, the contents did not have good scores from neither player groups. However, the ranking lists of players were considered as one of the best features.

The answers to the effectiveness of the game and sensors as motivational tools to physical activity were considered only from those participants who reported activity increase during the test period. This meant 17 subjects of whom 10 had tested the game at least once. Within the participants three reasons were considered to have positive effect to the physical activity change; the fitness tests performed before the pilot, the sensors itself and the upcoming second fitness tests. For example, from the Figure 5 can be seen that approximately 65 percent of the respondents told those three reasons having part or total effect on the change. The effectiveness of the actual game was considered poor, yet it was often stated that would the game had been more interesting, it would had been more motivating.
Figure 4: The average scores to different features of Space Pioneer with scale 1 5 (very poor - very good). 


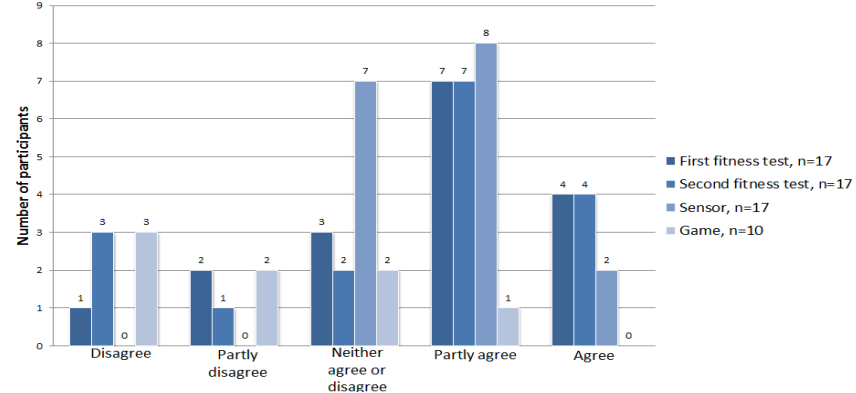

Figure 5: Answers to the motivating factors.

When studying the answers by the aspect of the sensors and the game it was noticed that among the 10 individuals having positive answer to the motivational factors of the sensors 2 considered that the fitness tests did not have effect on their change. However, the another one of these 2 was the only one considering the game having partial effect on the change. An another interesting detail was that two of the 17 participant who reported to increase their activity considered that none of the asked quantities effected to their change (sensors were only quantity that had neither agree or disagree answer). $\mathrm{F}$

\section{Discussion}

In the end, pilot research was challenging. The volunteer recruiting needed extra incentive and also the three months commitment was considered difficult. In this case, the incentive was the extra fitness tests promised after the three months for every one. Moreover, an error was made during recruiting: it was said to the participants that it is OK not to use the applications if they are not interested. Since the participation in the research was voluntary, then the requirement to use the applications would not been too harsh. From these problems encountered, a question arises that are effectiveness results achieved using persuasive inter- faces actually true or are the volunteers already beforehand more open to the technologies or ideas presented or are they more willing to change.

The first fitness tests, the sensors itself and the upcoming extra fitness tests were considered to motivate the men the most. Thus the effectiveness can be assumed to relate highly to the awareness of subjects' own physical condition as well as daily activity information. For example, the sensor itself gave information of the physical activity at a glance thus enabling the young men to be more conscious of their daily activity amounts easily.

The motivation factors of the actual game were considered poor and the game itself attracted only minor part of the volunteers. A partly reason is the busy way of life of young men and partly individual likings of games vary highly in the population of young men. Nevertheless, the incomplete version and lack of contents got negative feedback from those who played the game and the most of them neither considered the game to effect to their physical activity.

The final conclusion from the effectiveness of the approach is not unambiguous while the game was not interesting enough as motivating tool. However, the parts which raised the awareness of physical activity got positive feedback which information forms a good ground for future studies.

\section{Conclusions}

This article described how a computer game and wearable sensors based approach was used in promoting of physical activity for young men and the results achieved from a three months test. It can be concluded that the mock-up game had poor effectiveness while the awareness raising parts of the study were reported to motivate towards more physical active life. For example, the used sensors (pedometer, Polar Active, mobile phone software) had positive effect. 


\section{Acknowledgments}

This work was done as a part of MOPO study (ClinicalTrials.gov Identifier: NCT013 \76986). The authors would also like to thank Infotech Oulu and the Finnish Funding Agency for Technology and Innovation for funding this work.

\section{REFERENCES}

1. R Ahola, R Pyky, T Jämsä, M Mäntysaari, $H$ Koskimäki, TM Ikäheimo, ML Huotari, J Röning, H Heikkinen, and R Korpelainen. 2013. Gamified physica activation of young men - a Multidisciplinary Population-Based Randomized Controlled Trial (MOPO study). BMC Public Health 13, 32 (2013).

2. G Danaei, E L Ding, D Mozaffarian, B Taylor, J Rehm, C J Murray, and M Ezzati. 2009. The preventable causes of death in the United States: comparative risk assessment of dietary, lifestyle, and metabolic risk factors. PLoS Med 6, 4 (2009), e1000058, 1-23.

3. H Kinnunen, M Tanskanen, $H$ KyrÃülÃd'inen, and K R Westerterp. 2012. Wrist-worn accelerometers in assessment of energy expenditure during intensive training. Physiological Measurement 33, 11 (2012), 1841.

4. D J O'Gorman and A Krook. 2008. Exercise and the treatment of diabetes and obesity. Endocrinol Metab Clin North Am 37, 4 (2008), 887-903.

5. Omron WSIII. 2017. http://www.omronhealthcare.com/en/product/step_counters/HJ203_WSIII.html. (2017).

6. W Peng. 2009. Design and evaluation of a computer game to promote a healthy diet for young adults. Health Commun. 24, 2 (2009), 115-127.
7. Polar Active. 2017. http://www.polarusa.com/usen/support/product_support?product =29451e. (2017).

8. G. Ronda, P. van Assema, and J. Brug. 2001. Stages of change, psychological factors and awareness of physical activity levels in The Netherlands. Health Promot. Int. 16, 4 (2001), 305-314.

9. P. Siirtola and J. Röning. 2012. User-Independent Human Activity Recognition Using a Mobile Phone: Offline Recognition vs. Real-Time on Device Recognition. 9th International Symposium on Distributed Computing and Artificial Intelligence (2012).

10. S M Slootmaker, M J Chinapaw, J C Seidell, W van Mechelen, and A J Schuit. 2010. Accelerometers and Internet for physical activity promotion in youth? Feasibility and effectiveness of a minimal intervention [ISRCTN93896459]. Prev Med. 51, 1 (2010), 31-36.

11. R Telama and $X$ Yang. 2000. Decline of physical activity from youth to young adulthood in Finland. Med Sci Sports Exerc 32, 9 (2000), 1617-1622.

12. Tuunaa mopo. 2017. http://www.tuunaamopo.fi/sivu/fi/mopostudy_in_english/. (2017).

13. M H Van den Berg, J W Schoones, and T P M Vliet Vlieland. 2007. Internet-based physical activity interventions: a systematic review of the literature. $J$ Med Internet Res 9, 3 (2007), e26.

14. E M van Sluijs, A M McMinn, and S J Griffin. 2007. Effectiveness of interventions to promote physical activity in children and adolescents: systematic review of controlled trials. BMJ 335, 7622 (2007), 703, 1-13. 